\title{
ESQUERDAS LATINO-AMERICANAS E GASTO SOCIAL - HÁ COERÊNCIA ENTRE PROPOSTAS E PRÁTICAS?
}

Julia Sant'Anna

Fabricio Pereira da Silva

\begin{abstract}
Resumo
A proposta deste trabalho é analisar os gastos sociais de governos de esquerda ou centro-esquerda eleitos recentemente em países da América Latina. Serão cotejados os gastos em programas sociais focalizados, saúde e educação, com o objetivo de questionar o que as ações desses governos declaradamente progressistas estariam trazendo de novo no campo social em relação a seus antecessores, bem como quais concepções e práticas tradicionalmente estabelecidas eles estariam reproduzindo. Além disso, será destacada a relação entre propostas desenvolvidas antes da chegada ao poder e práticas posteriores desenvolvidas por esses governos progressistas.
\end{abstract}

Palavras-Chave: Partidos de Esquerda; Governos Progressistas; Gasto Social; América Latina; Eleições.

\begin{abstract}
This paper analyses social spending of left and center-left governments recently elected in Latin American countries. It compares the expenditure on targeted social programs as well as on health and education trying to identify what the actions these so-called progressive administrations would be bringing to the social field with regards to old practices. It also stresses the relation between proposals presented by these progressive actors before they were in power and what the put in practice afterwards.
\end{abstract}

Key-Words: Leftist Parties; Progressive Administrations; Social Spending; Latin America; Elections.

\section{Introdução}

Este trabalho analisa os gastos sociais de governos de esquerda eleitos recentemente em países da América Latina. São cotejados os gastos em programas sociais, saúde e educação, destacando o que as ações desses governos declaradamente progressistas estariam trazendo de novo no campo social em relação a seus antecessores e quais concepções e práticas tradicionalmente estabelecidas na região eles estariam reproduzindo. Assume destaque a relação entre as propostas desenvolvidas antes da chegada ao poder e as práticas posteriores desses governos. A questão de fundo do trabalho é se há coerência 
entre as propostas sociais das esquerdas latino-americanas quando estavam na oposição e suas atuais práticas governamentais.

Os países estudados são Chile, Brasil, Uruguai e Bolívia. No Chile, o Partido Socialista (PSCh), encabeçando a coalizão de centro-esquerda Concertação, elegeu Ricardo Lagos em 2000, e em 2006 sua sucessora Michelle Bachelet. No Brasil, o Partido dos Trabalhadores (PT) elegeu Luiz Inácio Lula da Silva em 2002, e o reelegeu em 2006. No Uruguai, a Frente Ampla (FA), que reúne de comunistas e ex-guerrilheiros a socialdemocratas e democratas cristãos, elegeu Tabaré Vázquez em 2004. Finalmente, na Bolívia, o Movimento ao Socialismo (MAS) elegeu Evo Morales em 2005. São partidos que, num período de crises de paradigmas para as esquerdas e de hegemonia neoliberal, conseguiram se destacar como alternativas efetivas de poder em seus respectivos países.

O tema da igualdade sempre foi central para as esquerdas, a ponto de ser o tema básico a distingui-las das direitas. Bobbio reconhece isso em sua definição de esquerda:

\begin{abstract}
o elemento que melhor caracteriza as doutrinas e os movimentos que se chamam de 'esquerda', e como tais têm sido reconhecidos, é o igualitarismo, (...) não como uma utopia de uma sociedade em que todos são iguais em tudo, mas como tendência, de um lado, a exaltar mais o que faz os homens iguais do que o que os faz desiguais, e de outro, em termos práticos, a favorecer as políticas que objetivam tornar mais iguais os desiguais (BOBBIO, 1995, p. 110) ${ }^{1}$.
\end{abstract}

Não haveria razão para supor que isso fosse diverso quanto aos setores hegemônicos das esquerdas latino-americanas atuais, tanto mais em sociedades marcadamente desiguais. Nota-se, evidentemente, a constante centralidade da temática social nos programas partidários e eleitorais consultados. A questão, portanto, para fugir do óbvio, é observar em que termos esse tema foi tratado, e por quais

\footnotetext{
${ }^{1}$ Bobbio é absolutamente sintético e, seguindo sua definição, todas as forças políticas aqui estudadas poderiam ser consideradas de esquerda. Além disso, os atores e organizações estudados se posicionam no que se convencionou considerar a "esquerda" dos sistemas partidários nos quais atuam e assim são compreendidos tanto pelos seus adversários quanto pelos especialistas que os estudam (ALCÁNTARA, 2004).
} 
metamorfoses ela passou nos anos anteriores à chegada dessas forças políticas ao poder em seus países.

$\mathrm{Na}$ primeira parte do trabalho, mapeamos e em seguida analisamos programas eleitorais, propostas partidárias e discursos de campanha do PSCh, do PT, da FA e do MAS. Destacamos as prioridades, os esboços de programas sociais e, de maneira geral, a concepção de gasto social - e em última análise de Estado, de sociedade civil e da relação entre eles - defendida por essas forças políticas. Apesar da maior atenção dedicada às campanhas eleitorais que levaram esses partidos ao poder, nós procuramos quando possível ${ }^{2}$ recolher formulações apresentadas por elas desde os anos 1980 - portanto, desde as transições democráticas nesses países. A dimensão diacrônica enriquece a análise, permitindo observar mudanças de prioridades e acompanhar a gênese de programas sociais e o papel de experiências locais nesse processo.

Na segunda parte do trabalho, analisamos as decisões no campo da política social tomadas pelos governos encabeçados por esses partidos. Os gastos com saúde, educação e as variações dos orçamentos destinados a programas sociais são observados ao longo dos anos com a intenção de apontar a existência ou não de mudanças significativas promovidas por governos progressistas. Os dados também são submetidos a comparações entre países, o que poderia indicar tendências comuns ou possíveis divergências.

Para garantir rigor metodológico, tais informações são extraídas de bases de dados de instituições que reúnem informações sobre os países da região e que garantem que os números possam ser trabalhados comparativamente, como Comissão Econômica para América Latina e o Caribe (CEPAL) e o Banco Interamericano de Desenvolvimento (BID). Dados mais recentes, relativos aos orçamentos de 2006 e 2007 - que ainda não se encontram disponíveis nas ferramentas de pesquisa regionais -, são observados sempre através de suas variações percentuais em relação aos períodos anteriores.

\footnotetext{
${ }^{2}$ Por limitações materiais, nem todo o acervo relativo ao tema pôde ser acessado. Além disso, no caso específico do MAS, ele só se organiza ao longo dos anos 1990, restringindo as possibilidades da análise.
} 
Por fim, a aplicação dos gastos sociais por quintis de renda traz a discussão a respeito da desigualdade de renda. A distribuição orçamentária pode indicar em que parcela da sociedade os investimentos sociais estão mais concentrados. Partidos de esquerda tradicionalmente defenderiam a necessidade de distribuir renda mesmo antes e independentemente do crescimento econômico. Através desta análise podemos, portanto, observar se as verbas destinadas às camadas mais pobres da sociedade realmente aumentaram percentualmente, ou seja, se os gastos sociais vêm se mostrando mais progressivos.

\section{Propostas sociais das esquerdas latino-americanas}

Nota-se nas formulações ao longo dos anos 1980 que, ao lado das transformações estruturais na sociedade, assumem destaque mudanças profundas no modelo e na relevância dos setores de saúde e educação. Ao lado das transformações que viriam em toda a organização social - não na forma de uma ruptura imediata, mas como o princípio de uma transição a uma sociedade socialista -, as forças de esquerda ocupando o aparelho do Estado iriam ampliar, reorganizar e sempre que possível estatizar as atividades ligadas àqueles setores.

Alguns exemplos podem ser citados, como a recorrente insistência do PT ao longo dos anos 1980 de saúde e educação pública e gratuita para toda a população, desde seu "Plano de Ação", de 1980, até o "Plano de Ação de Governo", de 1989 (PT,1998). Este último chega a propor tornar a educação pública, "em todos os níveis, exclusiva no prazo máximo de dez anos; isto é, o ensino é obrigação do Estado e o seu exercício deve ser entendido como concessão estatal" (PT, 1998, p. 420). Além disso, defende a estatização imediata ou progressiva dos serviços "estratégicos" e "essenciais" de saúde, aliada a um rigoroso controle da saúde privada. Propostas sempre desacompanhadas de qualquer programa social estruturado, bem como de propostas focalizadas. Sintomático é o prematuro surgimento de um tema caro ao PT em anos mais recentes, mas em enfoque distinto: a extinção da fome. Essa questão já é um dos pontos da primeira "Plataforma Eleitoral 
Nacional", de 1982 (PT,1998), mas ao invés da proposição de políticas dirigidas diretamente ao seu enfrentamento, a fome seria superada com políticas estruturais e estatizantes, como a estabilidade no emprego, um salário mínimo "real", a redução da jornada de trabalho e a venda de alimentos a preço fixo levada a cabo pelo Estado.

Outro exemplo interessante nos é dado pela "Plataforma Eleitoral" apresentada pelos socialistas chilenos durante a transição democrática em 1989, que propõe um claro enfrentamento da desigualdade através de políticas como a universalização da previdência, reforma tributária progressiva e renegociação da dívida externa. Um elemento de enfrentamento direto da desigualdade através de políticas sociais é sinalizado pela proposta de incremento do gasto social como forma de reverter "parcialmente" a dívida social herdada da ditadura. Podemos citar igualmente as proposições dos frenteamplistas durante a transição democrática uruguaia, traduzidas em suas "Bases Programáticas da Unidade", de 1984 (BAYLEY, 2005) - na qual a tônica é dada pelas propostas universalizantes como a criação de um sistema nacional de saúde e a expansão da educação pública.

É relevante salientar o caráter universalizante das propostas sociais nesse período. Em geral, defende-se uma atenção maior às populações e regiões mais desfavorecidas, mas considera-se sempre a expansão dos serviços sociais rumo à universalização sob o comando do Estado, nunca a sua focalização. Não são concebidos programas específicos, investimentos especiais, ou mencionadas racionalizações administrativas ou origem dos gastos. Naquele momento, para essas forças a igualdade seria estabelecida através da transformação radical da sociedade e da ampliação e estatização dos serviços ao longo desse processo - ou não seria.

No princípio dos anos 1990 começa a se notar uma lenta, porém consistente, mudança nas propostas dessas esquerdas. Começam a ser formulados alguns programas sociais específicos e nota-se uma abordagem mais progressiva e reformadora das desigualdades sociais. É possível apontar o papel importante que atuação parlamentar, experiências locais e regionais de governo, e participação no governo 
nacional (esta última no caso do PSCh) exerceram sobre essa transformação. O enfoque não é posto mais apenas sobre as atividades do Estado, que agora deve começar a dividir suas responsabilidades sociais ao menos com a sociedade civil organizada, e no limite com a iniciativa privada. Deve-se atentar para o peso que deve ter exercido nesse processo a necessidade mesma de legislar e governar dentro dos limites materiais e institucionais bem delimitados - e investir em reformas progressivas e mecanismos compensatórios.

Nesse sentido, a experiência da FA na administração de Montevidéu desde 1990 tem algo a nos dizer. Evidentemente, há uma ligeira diferença entre as propostas de transformações estruturais e universais defendidas pela frente nos anos 1980 e sua atuação efetiva em sucessivos mandatos na administração da capital uruguaia. Houve efetivamente uma inversão de prioridades no investimento público, ao ponto de $45 \%$ do orçamento municipal estar dedicado à área social (CHAVEZ, 2004). Iniciativas como a expansão do sistema municipal de saúde primária conviveram, no entanto, com uma gama de programas sociais específicos: capacitação de jovens em associação com ONGs e organizações comunitárias; centros sociais e passes livres para idosos; cotas de leite em pó para escolas e associações; planos de emergência oferecendo alimentos para as famílias pobres e abrigos para indigentes (BAYLEY, 2005).

As experiências parlamentares e de poder local do PT, bem como os debates levados a cabo no chamado "governo paralelo" ao Governo Collor (1990-1992), levaram o partido a formular propostas mais elaboradas, se preocupar com a origem dos gastos necessários, e com medidas imediatas e pontuais. Um bom exemplo é a proposta de "Política Nacional de Segurança Alimentar", que procurava combater a fome através da combinação de medidas tanto imediatas quanto estruturais, que permitiriam "a conquista da cidadania para milhões de excluídos, o resgate da solidariedade e da ética como valores na sociedade e (...) a formulação de alternativas para a produção e a distribuição de riqueza e renda" (PT, 1998, p. 546). Outro exemplo é o surgimento do tema da garantia de renda mínima, defendido pela 
primeira vez no I Congresso do PT ocorrido em 1991, e incluído nos programas de governo propostos pelo partido a partir de 1994. Trata-se da primeira referência nos documentos do partido a um programa social especificamente direcionado aos setores mais pobres da população, oferecendo a eles transferência focalizada e direta de recursos estatais. Esse foi um dos motes da atuação parlamentar petista nos anos seguintes, e se desdobrou em versões como o Bolsa Escola e o Bolsa Família, introduzidos em diversas administrações desde então e presentes nos documentos do partido a partir de 1997.

No caso do PSCh, é evidente ao longo dos anos 1990 a necessidade de moderação programática às limitações impostas estruturalmente pela transição democrática negociada e por sua participação na aliança e nos governos concertacionistas. A intenção de se adequar às limitações e possibilidades fica evidente nas "Resoluções do Congresso Geral Extraordinário", de 1998. Nelas, se acena para a necessidade de associar a busca da igualdade ao desenvolvimento econômico logrado durante os governos da Concertação - através da progressiva provisão de bens e serviços aos mais pobres e do avanço na proteção social aos mais desfavorecidos. Sintomática das limitações vivenciadas pela transição e pela aliança concertacionista ao PSCh é a autocrítica elaborada já durante o governo Ricardo Lagos, no XXVI Congresso do partido (2001). Trata-se de uma formulação que escapa à delimitação temporal estabelecida, mas que pode lançar uma luz indispensável sobre a trajetória recente do partido:

\begin{abstract}
En relación con la transición democrática, que es otro de los procesos de cambios que caracterizan la época, se concibe como un proceso inconcluso en lo económico, político y social. En lo económico, porque no se han logrado avances significativos en materia de equidad social. En lo político, porque aún no hemos logrado instalar una democracia plena, ya que persisten los enclaves autoritarios y hay ausencia de un proyecto de país tanto en el Partido Socialista como en la Concertación. En lo social, principalmente por el énfasis asistencialista de las políticas sociales y la escasa participación social y ciudadana (Site do PSCh, 2008, grifos nossos ${ }^{3}$ ).
\end{abstract}

\footnotetext{
${ }^{3}$ Até o final do texto, todas as citações em negrito foram grifadas por nós.
} 
Ao lado da tradicional luta contra a desigualdade, começa a ganhar espaço a noção da exclusão, a necessidade de se oferecer cidadania a setores que estariam à margem do consumo e da produção - abrindo brechas a uma associação muitas vezes sem maiores mediações entre cidadania e acesso à produção e ao consumo. $\mathrm{O}$ apelo aos trabalhadores ou aos oprimidos começa a ser substituído pelo chamado à cidadania e pelo enfoque em temas éticos como o combate à corrupção. A construção de uma sociedade alternativa começa a ser posta num futuro distante, cedendo espaço a propostas de inclusão dos marginalizados ao capitalismo. Essa metamorfose ao longo dos anos 1990 é a tônica das esquerdas latino-americanas hegemônicas.

\section{Propostas sociais vitoriosas}

Apresentamos agora as propostas sociais elaboradas nas eleições que levaram os partidos de esquerda estudados ao poder. No Chile, o "Programa de Governo de Ricardo Lagos" propôs a continuidade do crescimento econômico alcançado pelos governos concertacionistas hegemonizados pelos democrata-cristãos, mas direcionado agora para a igualdade:

\footnotetext{
La igualdad de la que hablamos es la que busca crear oportunidades; la que permite la justicia social, la desconcentración económica, política y territorial. (...) Sin un crecimiento económico que genere más y mejores empleos no cerraremos la brecha de la desigualdad. (...) Sabemos que la igualdad no puede ser creada artificialmente por el Estado. Pero tampoco nace automáticamente del mercado. El Estado y el mercado son sólo instrumentos para apoyar la dignidad humana. Para ello el gobierno debe cumplir sus responsabilidades como garante de los derechos sociales básicos de las personas. Un gobierno que presta una atención preferente a los débiles y a los que más necesitan (Site do Governo do Chile, 2008).
}

Propõe-se 0 aumento dos gastos em saúde e educação direcionados aos setores mais pobres da população (não através do aumento de redes estatais, mas do oferecimento de apoios financeiros aos mais necessitados), um apoio mais efetivo aos desempregados e pensionistas empobrecidos, e a expansão da cobertura da seguridade 
social "na medida das possibilidades fiscais". A proposta de crescimento econômico com igualdade, bem como a definitiva conclusão da transição chilena, dá a tônica do programa: ou seja, podemos afirmar resumidamente que se defendem mudanças na continuidade.

O PT apresentou em 2002 suas "Diretrizes do Programa de Governo", procurando conjugar mudanças estruturais com medidas emergenciais. As mudanças estruturais poderiam ser resumidas em um novo modelo de desenvolvimento que priorizasse a produção e o emprego, e que modificasse o perfil do Estado para um maior e mais eficiente gasto social. Com isso, se poderiam universalizar os serviços e direitos sociais básicos, defender o direito ao trabalho e à seguridade social, bem como incluir as enormes parcelas de excluídos. Tais transformações estruturais deveriam ser combinadas com medidas emergenciais, tais como a instituição da renda mínima associada à educação (Bolsa Escola) na direção de uma "renda básica de cidadania" como direito de todos, e o Fome Zero ${ }^{4}$, política de segurança alimentar para garantir o acesso a uma cesta básica aos mais necessitados. 0 programa explicava que

O financiamento desse conjunto de políticas públicas vinculadas à garantia de direitos sociais supõe, evidentemente, uma profunda alteração no perfil do gasto público. Tal alteração, que deve criar um espaço considerável para o gasto social (assim como para os investimentos em infra-estrutura, ciência e tecnologia), resultará da implementação global do novo modelo de desenvolvimento - o que envolve a redução da vulnerabilidade externa e a recomposição das finanças públicas (Site do PT, 2008).

No centro desse programa estaria uma mudança fundamental: o fim da noção de independência da economia em relação ao social, superando dessa forma as políticas sociais "assistenciais" e "compensatórias" (críticas diretas ao governo neoliberal anterior). Tal proposta de inversão foi relativizada ao menos em parte com a apresentação durante a campanha da "Carta ao Povo Brasileiro", assinada por Lula, que reconhecia a necessidade de um período de

\footnotetext{
${ }^{4}$ Desenvolvido pelo Instituto Cidadania (2001), think tank ligada informalmente ao PT.
} 
transição para o novo modelo de desenvolvimento calcado no crescimento produtivo, no emprego e na justiça social. Propunha-se o "respeito aos contratos e obrigações do país", o "controle da inflação", o "equilíbrio fiscal como um meio, não um fim", a "preservação do superávit primário", o ordenamento das contas públicas e o "crescimento econômico com estabilidade e responsabilidade social" (Site do PT, 2008).

O programa da FA apresentado em 2004 para a área social, denominado "Uruguai Social", abandonou qualquer perspectiva na direção do combate às desigualdades e centrou sua atenção no combate à pobreza, especialmente à pobreza extrema. Conjugado com medidas estruturais voltadas a esse objetivo tais como a retomada do papel do Estado como organizador e executor de políticas sociais e reformas e expansões na saúde e na educação, foi proposto o "Plano Nacional para a Emergência Social" (Panes), temporário e com objetivos precisos. Nas palavras de Tabaré Vázquez durante a campanha, tratava-se de "'un sistema de medidas de diverso tipo y alcance que apunten a atender la emergencia social a través de acciones de asistencia y promoción'" (BAYLEY, 2005, p. 194). Efetivamente, como tema central no programa, o Panes prometia, através de medidas como entrega de alimentos, transferência direta de renda e investimentos em escolas e postos de saúde em regiões pauperizadas,

1- Garantizar un nivel básico de alimentación al conjunto de la población que hoy no lo alcanza. 2Brindar cobertura asistencial integral a través de un sistema de atención de salud básico a sectores actualmente excluidos del mismo. 3- Dar respuesta efectiva y de emergencia a las personas en situación de indigencia (...) 4- Contener y reducir la pobreza en los sectores más vulnerables. 5- Reincorporar al sistema educativo a los alumnos que lo han abandonado (Site da FA, 2008).

\section{O caso do MAS}

Por fim, tratamos separadamente do MAS. Em certo sentido, e ao menos aparentemente, sua trajetória até o poder apresenta aspectos distintos dos outros casos estudados, por ter começado a se estruturar na segunda metade dos anos 1990, e por ter chegado ao poder em 
2005 apresentando propostas ligeiramente mais radicais em comparação aos outros partidos. Em seu programa desenvolvido em 2001 e apresentado nas eleições de 2002, o MAS propunha educação e saúde públicas universais e esforços no sentido da redistribuição da renda nacional. No entanto, já chamava atenção para o tema da exclusão e justificava suas preocupações sociais lançando mão dos Direitos Humanos:

El MAS denuncia que más de 1.500 millones de personas en el mundo disponen de menos de un dólar por día para satisfacer sus necesidades. La Salud, una alimentación adecuada, la educación y el desarrollo son derechos humanos que nada tienen que ver con la beneficencia ni con la limosna, por tanto, deben ser atendidos por Estado y la Sociedad civil como obligaciones ineludibles (Site do MAS, 2008).

O programa de governo apresentado nas eleições de 2005 (que guindaram o partido ao poder) defendeu uma "política social de atención al ser humano en toda su dimensión, donde serán satisfechas educación, salud y seguridad social para toda la población del campo y las ciudades", e afirmou que "Más que buscar el progreso o el desarrollo, procuraremos un mundo feliz y una vida de pleno gozo, humano, tal como lo vivieron nuestros antepasados" (Site do MAS, 2008). Trata-se de concepção distinta da refletida nos programas de governo apresentados pelos outros partidos estudados em suas campanhas vitoriosas e mais próxima das propostas defendidas por eles nos anos 1980 - acrescida do seu particular elemento indigenista. No entanto, a preocupação com os temas da integração e inclusão já dão a tônica deste programa. Além disso, podemos encontrar diversas preocupações e propostas mais específicas e focalizadas, tais como:

\footnotetext{
Priorización [na saúde] a las familias con limitaciones económicas (...) Seguridad alimentária para toda la población que lo requiera, con el uso de la producción agrícola local y la organización de ollas comunales, desayuno escolar equilibrado y dotación de alimentos a las mujeres embarazadas y post parto. (...) Diseño y ejecución de planes educativos de igualación de oportunidades orientadas a las poblaciones con mayores niveles de marginación y exclusión (...)
} 
Plan Nacional para el acceso y permanencia en la educación: propuesta integral que según las características y necesidades incluye desayuno y almuerzo escolar, becas, seguro de salud, internados y transporte escolar (Site do MAS, 2008).

Assim, para além de um discurso ligeiramente mais radical e alternativo, podemos notar diversas semelhanças entre os programas sociais do MAS e os dos outros casos estudados, apontando tanto para sua eventual caminhada - num espaço menor de tempo - na mesma direção percorrida pelos outros partidos, quanto para possíveis práticas de governo mais assemelhadas às deles.

\section{Gasto social na América Latina}

São bem recentes os estudos que buscam relações entre os níveis de gasto social e o contexto político dos países da América Latina. Brown e Hunter (1999) investigaram a relação entre democracia e gasto social no período de 1980 a 1992, concluindo que, em contextos de crise econômica - com baixo nível de renda per capita e crescimento negativo - governos autoritários tendem a diminuir a verba de programas sociais, enquanto governos democráticos tendem a aumentá-la. Em períodos de estabilidade, no entanto, quase não há diferença no comportamento de ambos.

Avelino Filho (2000) afirma que as democracias latinoamericanas mostraram um impacto positivo sobre as prioridades orçamentárias dos gastos sociais entre 1980 e 1994. Ao investigar a situação em 17 países ao longo desses 14 anos, ele destaca também que, se por um lado a democracia favorece o aumento de gastos sociais, por outro não se pôde comprovar a boa aplicação dele. A conclusão é de que a democratização não contribuiu como se esperava para a melhoria do bem-estar do pobre. O aumento dos gastos teria beneficiado as classes médias e regiões urbanas, especialmente nos países com maior gasto social per capita (entre eles, Argentina, Brasil e Chile).

Kaufman e Ubiergo (2001) se concentram nas reformas econômicas para tentar identificar mudanças comuns aos países latinoamericanos que foram se abrindo comercialmente para o resto do 
mundo entre 1973 e 1997. Na análise do gasto social agregado, os pesquisadores concluíram que no curto prazo a abertura comercial tem impacto negativo sobre o orçamento social e não necessariamente estimula investimentos em saúde ou educação. A única evidência encontrada acerca dos efeitos da abertura comercial e sobre os gastos sociais é a redução dos investimentos em seguridade social.

Tomando o período entre 1980 e 1999, Santos (2006) realizou análises econométricas para concluir que governos de esquerda que têm maioria legislativa tendem mesmo a gastar mais no setor social. Governos de direita com maioria legislativa, por sua vez, investem menos no social do que governos de direita minoritários ${ }^{5}$.

De uma maneira geral, estudos comparados sobre a evolução dos orçamentos públicos sociais em países da América Latina chamam atenção para a queda dos gastos sociais entre 1981 e o início da década de 1990. A maior baixa na região foi sentida em 1990 (OCAMPO, 1998), e tais cortes poderiam ser explicados como conseqüência das crises da dívida sofridas por muitos países da região e refletidas internacionalmente. Considerando-se a tendência média, a América Latina recuperou os valores percentuais de gastos sociais de 1981 apenas no ano de 1993. Desde as graves crises, com lenta recuperação, o gasto público social tem aumentado de maneira sistemática desde começo dos anos 1990. Entre 1990 e 2000, o crescimento médio do orçamento social chegou a 58\%, e reduções posteriores foram apenas marginais (COHEN, 2005). A edição de 2005 do "Panorama Social da América Latina", da CEPAL, conclui que os recursos por habitante destinados a educação, saúde, habitação, segurança e assistência social aumentaram em 39\% entre o começo dos anos 1990 e o biênio 20022003. O percentual do gasto público social em relação ao PIB se elevou em mais de dois pontos percentuais (de $12,8 \%$ para $15,1 \%$ ).

\section{Novos governos de esquerda}

\footnotetext{
${ }^{5}$ A análise mostrou melhores resultados quando considerado o gasto social agregado em educação e saúde como porcentagem do gasto público total.
} 
A seguir, tratamos separadamente os casos dos quatro países analisados. Quando possível, os gastos em saúde, educação e assistência social serão analisados comparativamente. Números mais recentes, no entanto, serão observados no contexto de cada país, isoladamente 6 . Assim como já esperado em relação ao PIB per capita, os países aqui tratados posicionam-se em variados patamares no que se refere à fração destinada ao gasto social sobre o gasto total. O Gráfico I ilustra o fato de que, apesar de ter mostrado um aumento de $289 \%$ entre 1990 e 2003, o gasto social per capita boliviano do fim deste período representa apenas 24\% do valor brasileiro entre 1990 e 1991 .

Gráfico I

\footnotetext{
${ }^{6}$ A análise direta dos orçamentos nacionais nem sempre se presta a comparações precisas, uma vez que cada país mantém uma maneira própria de organizar suas dotações orçamentárias. No caso do Brasil, por exemplo, o orçamento federal não é suficiente para a análise do gasto em educação, uma vez que as três esferas (federal, estadual e municipal) administram recursos deste setor. Além disso, optamos por apresentar dados os mais atualizados possíveis, mesmo reconhecendo que há nessa opção o risco de algumas imperfeições.
} 


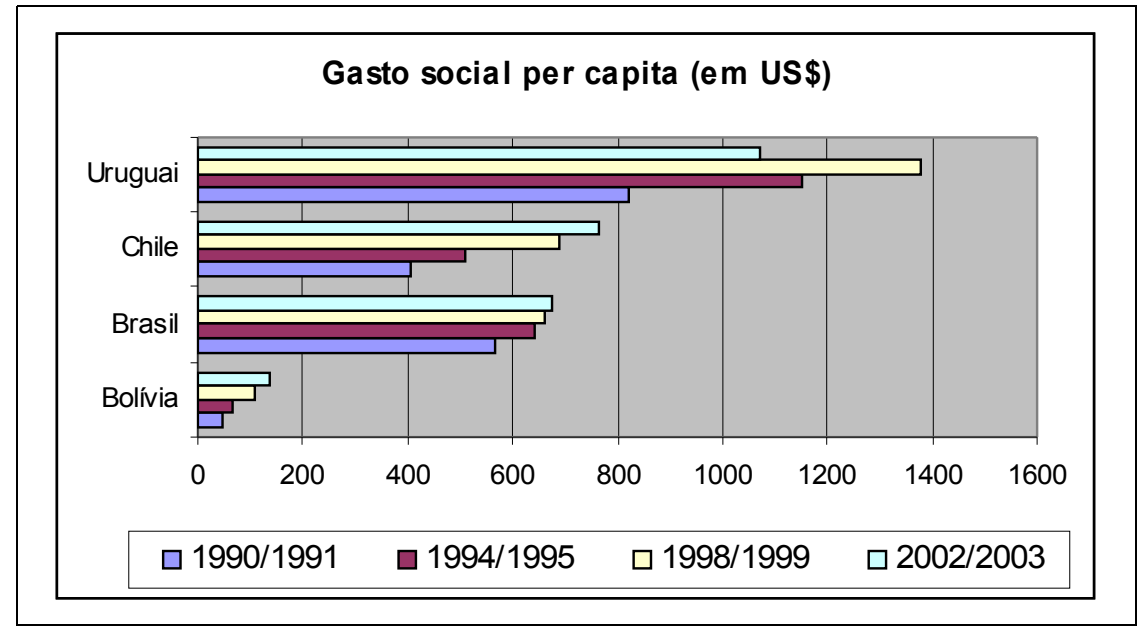

Fonte: CEPAL, 2005.

Grandes transformações em relação ao gasto social no Chile vêm de antes da chegada do PSCh ao poder, com a eleição de Ricardo Lagos, em 2000. Desde a redemocratização do país, em 1990, os gastos sociais vêm apresentando importantes altas, tanto no que diz respeito aos valores per capita (Gráfico I), quanto no que se refere ao percentual do gasto social sobre o gasto público total (Gráfico II). Em meados da década de 1990, já sob o governo da Concertação, foram recuperados os níveis de gasto social do início da década de 1970 (ILLANES e RIESCO, 2007). Durante a gestão de Ricardo Lagos, pôde-se observar a manutenção do índice de crescimento em cerca de dois pontos percentuais do gasto social sobre o gasto total.

Gráfico II

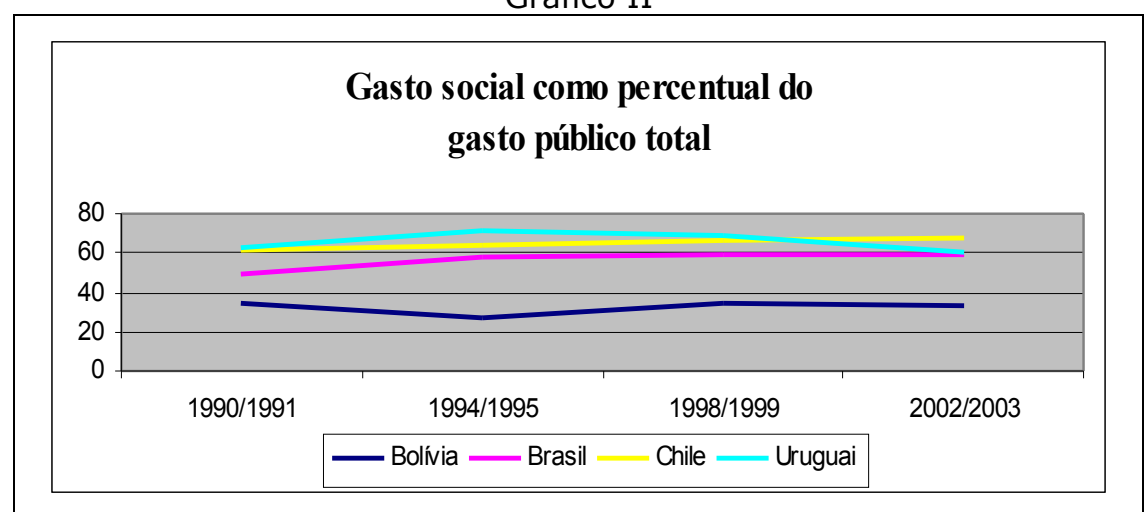

Fonte: CEPAL, 2005. 
A análise desagregada dos gastos em educação e saúde mostra, no entanto, que o Chile apresentou ascensão nos quatro indicadores abaixo, ao contrário do que acontecia no mesmo período nos demais países analisados, onde os governos de esquerda ainda não haviam chegado ao poder. Dos quatro países analisados, entre 2002 e 2003, o Chile foi o único a manter evolução ascendente, mesmo sobre já relativamente altos percentuais destinados ao setor, como se pode ver nos Gráficos III, IV, V e VI.

\section{Gráfico III}

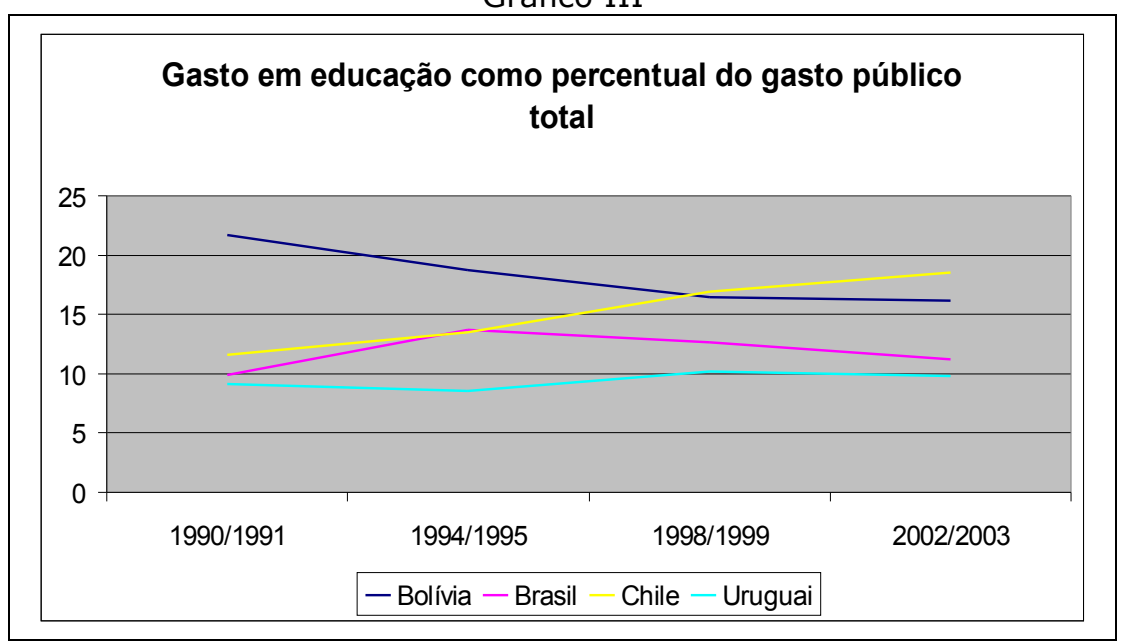

Fonte: CEPAL, 2005.

Gráfico IV

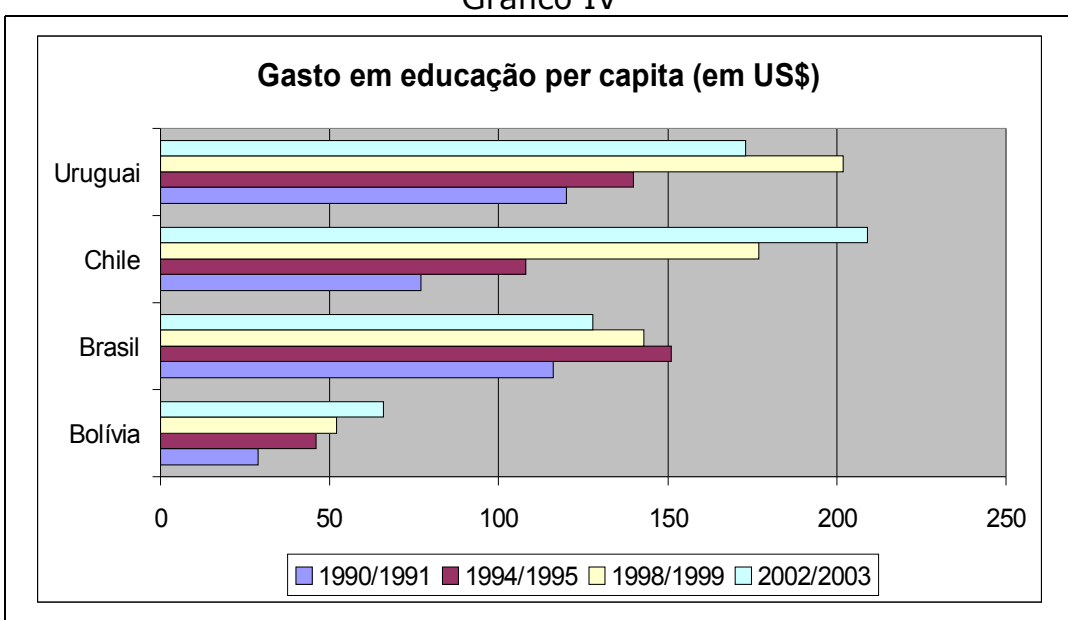

Fonte: CEPAL, 2005.

Gráfico V 


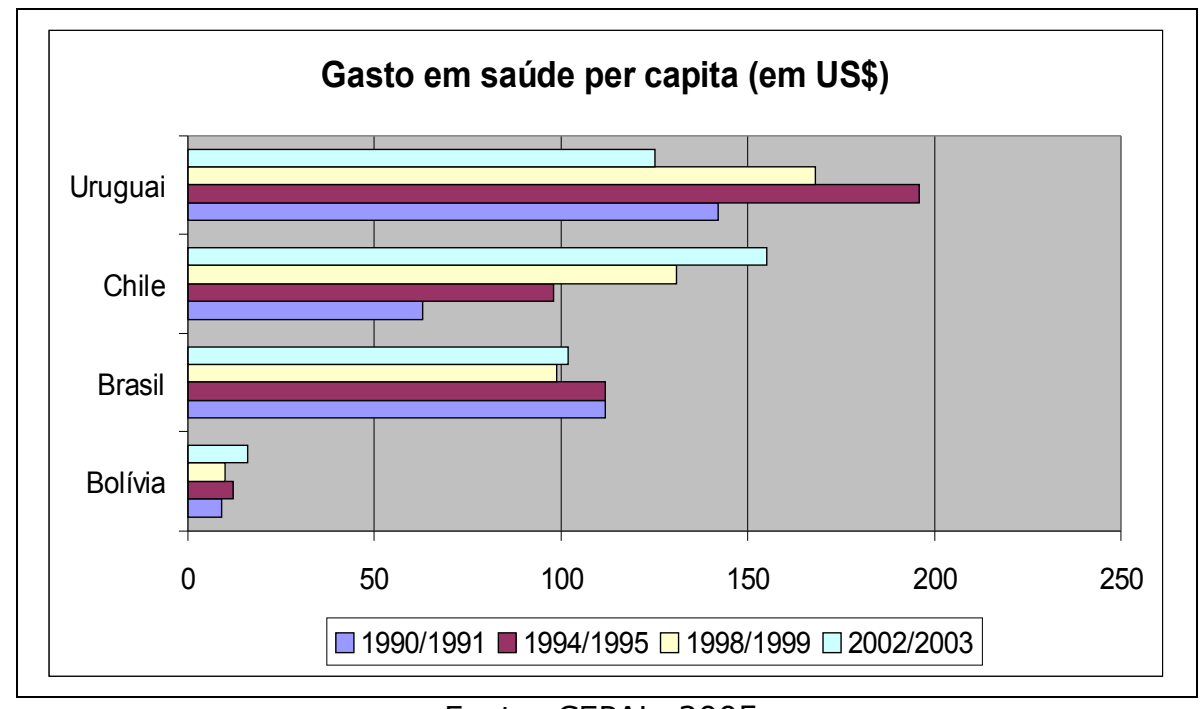

Fonte: CEPAL, 2005.

Gráfico VI

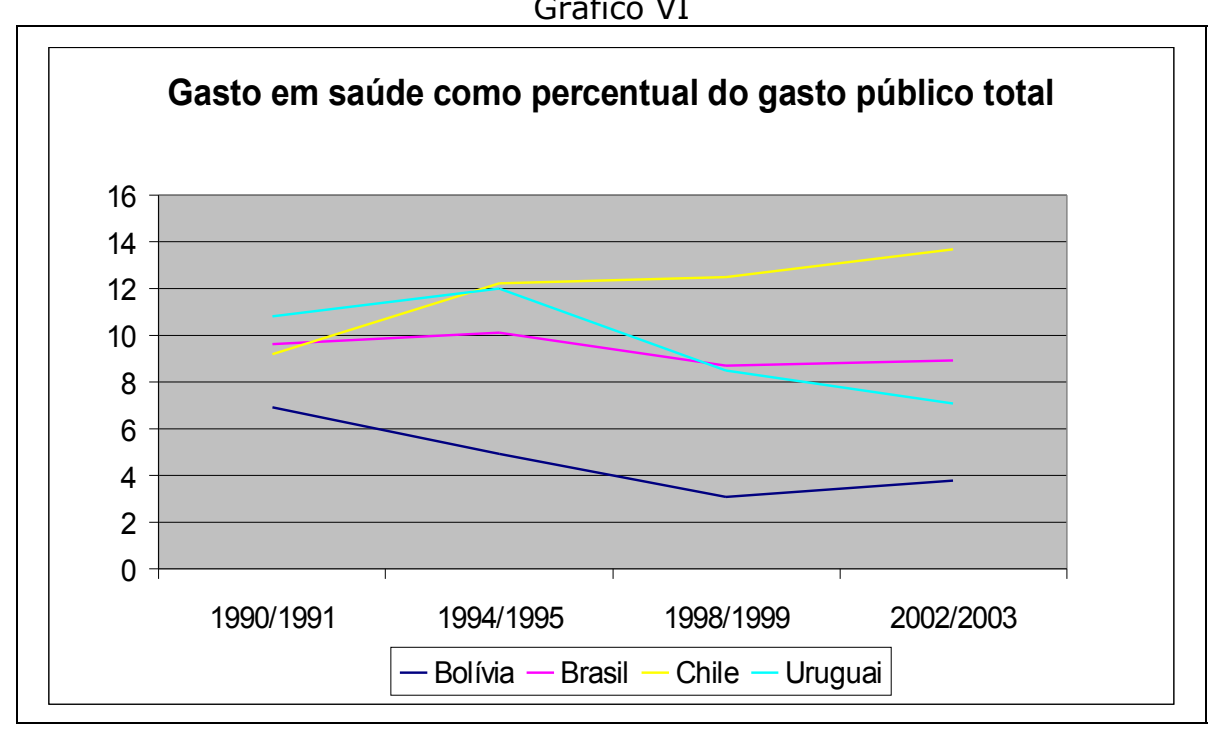

Fonte: CEPAL, 2005.

Em suas prestações de contas, o governo Lagos chama atenção para a preocupação com a progressividade do gasto social. Em 2003, $42 \%$ do gasto público dos principais programas de saúde, educação e subsídios monetários se concentraram nos $20 \%$ de lares de rendas mais baixas do país (CHILE, 2004). Faz parte do esforço de maior progressividade do gasto público o uso de políticas de focalização, que tem no Chile Solidário seu maior exemplo no país. O programa foi criado em 2002 pelo governo Lagos para fazer baixar os índices de indigência do país, concedendo à população que vive em pobreza extrema 
subsídios monetários e apoio educacional e nutricional. Em 2007, já sob o segundo governo socialista, de Michelle Bachelet, o Chile teve sua maior expansão orçamentária $(8,9 \%)$ desde que o país voltou ao regime democrático. O aumento dos gastos foi observado principalmente na área social. A fatia referente à saúde, educação e habitação - que representa atualmente $68 \%$ dos gastos públicos - sofrerá um aumento de $11 \%$. Segundo analistas, a medida foi beneficiada principalmente pela disparada do preço mundial do cobre?.

Os gráficos acima mostram grande oscilação dos indicadores do Brasil na década de 1990. Há um tímido crescimento do gasto social per capita (Gráfico I) e uma estagnação em relação a sua participação no gasto público total (Gráfico II), mantido em torno de $58 \%$. O que mais chama atenção na análise entre 1994 e 2003 no Brasil é a queda do gasto em educação: em níveis per capita a queda foi de $18 \%$, em participação sobre o gasto público total, 22\%.

Pochmann (2005) faz uma comparação entre os biênios 20012002 e 2003-2004, apontando uma involução do gasto social per capita federal de quase 8,5\% entre 2001 e 2004. O Gráfico VII ilustra as demais variações neste período e exibe o grande crescimento do orçamento destinado à assistência social, de 17,25\%. Se, por um lado, é importante chamar atenção para o fato desse grande crescimento se apresentar sobre patamares baixos, por outro, nos serve para começar a identificar uma tendência que vem se tornando cada vez mais visível no país no início dos anos 2000. É no Gráfico VIII que este argumento mostra-se mais claro. No período em que políticas focalizadas e, mais especificamente, programas de transferência de renda, como o Bolsa Escola e o Bolsa Família, passam a ganhar mais estímulo interno e externo e mais investimento, observa-se uma inversão de participação dos gastos com educação e assistência social no orçamento. Dados do documento "Orçamento Social do Governo Federal" (BRASIL, 2005), desenvolvido pela Secretaria de Política Econômica do Ministério da

7 Assim como na Venezuela, portanto, a situação macroeconômica favoreceu o investimento social, fato que faz com que se atente para não considerar gasto social isoladamente do contexto externo. Nos últimos anos, tanto na Venezuela, por causa da alta do petróleo, quanto no Chile, por causa do cobre, os governantes estão em condições mais favoráveis para um aumento de gastos. 
Fazenda, mostram que os recursos destinados à assistência social ultrapassaram as verbas de educação em 2001. Esta diferença percentual que, em 2002, era de 0,55 ponto percentual, chega a 1,29 ponto de diferença em 2004, primeiro ano com orçamento aprovado durante o governo Lula, empossado em 2003. Nota-se que, de 2003 para 2004, saúde, educação e assistência social apresentaram alta em relação ao orçamento social. Esta última, no entanto, registrou a maior alta, de 0,49 ponto percentual, seguida pela saúde, com 0,33. A educação teve de longe o crescimento mais tímido: 0,04.

Gráfico VII

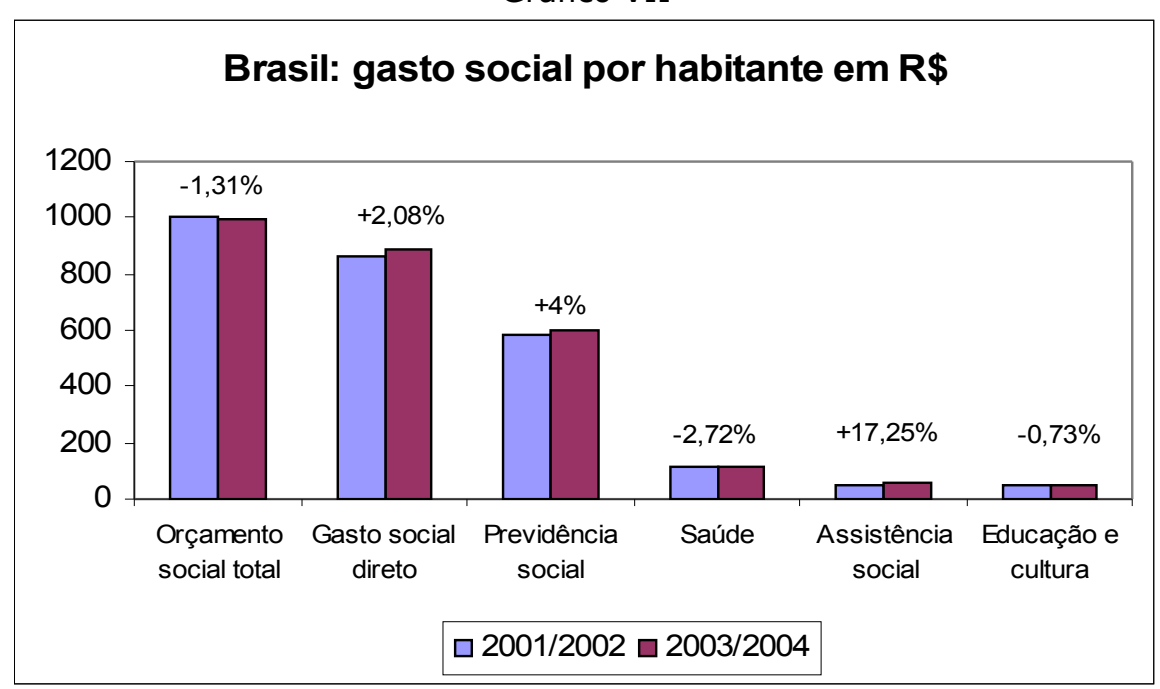

Fonte: POCHMANN (2005).

Gráfico VIII 


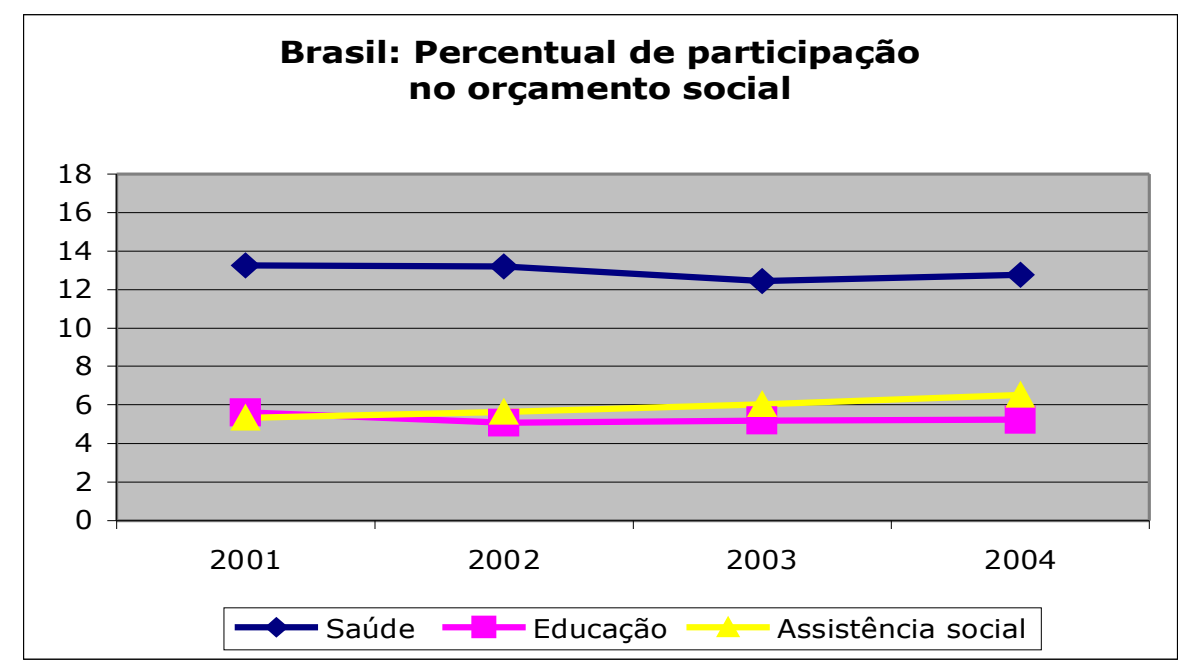

Fonte: BRASIL (2005).

Enviado ao Congresso pelo Executivo em 31 de agosto de 2007, a proposta de orçamento para 2008 sugere uma reaproximação dos gastos em educação e assistência social. Entre os ministérios que mais aumentariam seus orçamentos em 2008 destacam-se exatamente o da Saúde, o da Educação e o de Desenvolvimento Social e Combate à Fome. Na Tabela I pode-se observar que, apesar de manter ainda o menor orçamento entre os três listados, a proposta sugere crescimento de $32,2 \%$ no orçamento do Ministério da Educação, o que seria o maior aumento percentual entre as três principais áreas sociais. Sugere-se ainda que o orçamento do Bolsa Família passe de 8,6 bilhões para 10,4 bilhões em 2008.

Tabela I

Brasil: proposta de orçamento para 2008 (R\$ bilhões)

\begin{tabular}{c|c|c|c}
\multicolumn{2}{c}{ Brasil: proposta de orçamento para 2008 (R\$ bilhoes) } \\
\cline { 2 - 4 } & 2007 & 2008 & $2007-2008$ \\
\hline Saúde & 39 & 42,5 & $+8,9 \%$ \\
\hline Desenv. social & 10,5 & 13,2 & $+25,7 \%$ \\
\hline Educação & 9,6 & 12,7 & $+32,2 \%$ \\
\hline
\end{tabular}

Fonte: Site do Ministério do Planejamento do Brasil.

A respeito do Uruguai, os gráficos de I a IV mostram que a crise econômica vivida no início dos anos 2000 refletiu-se diretamente em queda nos gastos sociais. FLOOD, GRAU e MELGAS (2005) analisaram o período e identificou estratégia cíclica - e não anticíclica, que evitaria 
uma queda nos gastos sociais exatamente no período em que eles seriam mais necessários - acrescentando que:

Tres herramientas básicas de política social no han sido utilizadas hasta el momento con el rigor necesario para conducir a una mayor eficacia y eficiencia en su ejecución: la focalización de los programas, la conformación de un Registro Único de beneficiarios y la institucionalización de un sistema de información social (FLOOD, GRAU e MELGAS, 2005, p. 2).

Tabaré Vázquez foi eleito em 2005 com a promessa de alcançar gastos de $4,5 \%$ do PIB em educação. Os debates sobre as definições dos orçamentos de 2006 e de 2007 giraram em torno deste compromisso de campanha, com diversos grupos sociais pressionando o governo para que a meta seja rapidamente atingida.

Até o momento, no entanto, a principal ação da política social de Vázquez foi em direção à focalização do gasto e ao desenvolvimento de mecanismos de gestão de políticas de transferência de renda. O Panes entrou em vigor com a posse do presidente frenteamplista, dirigido às famílias cuja renda per capita seja inferior a uma cesta básica, o equivalente a US\$56. Estima-se a população alvo em 200 mil pessoas, localizadas no último quintil de renda. Nos mesmos moldes do Bolsa Família, os beneficiários do programa uruguaio recebem a chamada "renda cidadã" e devem cumprir contrapartidas, como garantir a freqüência de filhos na escola. Está prevista para o início de 2008 a extinção do Panes - que, como o nome diz, funcionaria apenas em caráter emergencial - e a implantação do "Plano de Equidade". Ainda não estão completamente definidas as características do novo programa, mas sabe-se que haverá um aumento no valor das transferências, que variarão de acordo com a quantidade de filhos.

A Bolívia quase triplicou o gasto social per capita entre 1990 e 2003, mas seus níveis continuam sendo de longe os mais baixos da região. Um relatório do Unicef, no entanto, destaca entre as conquistas na análise do gasto entre os anos de 2000 e 2004:

si bien el gasto público total decreció en 4,5 puntos porcentuales del Producto Interno Bruto (PIB), alcanzando el 35,2\% del PIB en 2004, tanto el Gasto Social Funcional como el Gasto Social para la Niñez 
lograron un incremento en sus recursos del 0,4\% del PIB en el año 2000 al 1,2\% en el año 2004. (...) Entre los años 2000 y 2004, el Sector Público en Bolivia presentó una evidente disminución de sus ingresos que se explica, fundamentalmente, por la necesidad de evitar que el déficit fiscal aumente a límites insostenibles. Los sectores no sociales fueron los más afectados por dicha reducción, a diferencia de los sectores Educación, Salud y Protección Social que se caracterizan por su inflexibilidad (UNICEF, 2006, p. 14).

Os lucros do processo de nacionalização iniciado por Evo Morales ainda não foram revertidos em mais investimento no setor social. No orçamento desenhado para 2007, o social não esteve entre as grandes prioridades do governo Morales - o investimento de 5,6\% foi considerado uma baixa em relação ao ano anterior -, que se concentrou no setor produtivo (transportes e desenvolvimento agropecuário), que receberia ao longo deste ano $79,8 \%$ do orçamento destinado a investimentos do governo.

Assim como no Uruguai, políticas de transferência de renda vêm ganhando espaço na agenda pública boliviana após a posse de um governo progressista. Criado pelo decreto 28.899 em outubro de 2006, o Bono Juancito Pinto concede uma doação do equivalente a US\$26 por ano a 1,2 milhão de menores. A doação às crianças, necessariamente matriculadas na rede pública entre a $1^{a}$ e a $5^{a}$ série, é feita em duas parcelas e entregue pelas Forças Armadas.

\section{Conclusão}

Até aqui mapeamos as mutações sofridas pelas concepções e propostas sociais das principais forças de esquerda latino-americanas. Agora pretendemos apresentar algumas chaves para compreendê-las. As transformações apresentadas até aqui só podem ser entendidas a partir de fenômenos que marcaram indelevelmente a trajetória desses partidos na última quadra histórica. Podemos nos referir a três importantes movimentos sócio-históricos: crise do "socialismo real" e do pensamento marxista; crise do desenvolvimentismo e ascensão do neoliberalismo; e o processo de redemocratização na região. 
A crise vivenciada pelas esquerdas não se restringiu à derrocada do chamado "socialismo real", mas a uma profunda crise do pensamento marxista - até então o principal referencial teórico no campo das esquerdas. Mais do que isso: houve nas últimas décadas o refluxo das utopias e das apostas no futuro, um abalo de qualquer ideário que propusesse alternativas, o que configurou a sensação de que havia um "pensamento único". Da mesma forma, não se deu apenas uma crise do "socialismo real", mas sim de qualquer força política ou governo que pusesse sua ênfase, mesmo que de forma diluída, na redistribuição de riquezas ou na igualdade. Assim, tal crise não atingiu apenas os movimentos e organizações relacionadas diretamente às experiências do "socialismo real", mas amplificou as dificuldades que começavam a enfrentar também a social-democracia e as experiências de Estados de bem-estar social.

Diagnosticou-se um esgotamento das diversas formas "Estadocêntricas" ou "partido-cêntricas". Isso tem relação direta com a reestruturação produtiva vivenciada pelo capitalismo nas últimas décadas, passando de maneira mais ampla pela crise da "modernidade organizada" (WAGNER, 2004) caracterizada pela centralidade estatal, pela hierarquização e centralização dos meios de produção capitalista, por identidades calcadas na classe e na ocupação, e pela democracia de massas com seus respectivos partidos de massas (BOLTANSKI e CHIAPELLO, 2002; GIDDENS, 1991). Essa transformação global se manifestou na América Latina em grande parte através da crise do desenvolvimentismo. A resposta a essa crise se deu pela redução dos subsídios e das próprias dimensões de um Estado em crise e desmoralizado; da liberalização comercial e abertura ao capital financeiro e investimentos internacionais em expansão num contexto de globalização e descentralização produtiva; e da redução e focalização dos investimentos sociais em meio a uma expansão do desemprego e das formas de trabalho informais e a uma pulverização e renovação identitária.

Na América Latina, a ascensão da política neoliberal coincidiu com os momentos decisivos da redemocratização, e a consolidação das 
novas democracias teve que se dar sob o signo desse pensamento. Essa combinação produziu fenômenos de difícil resolução para as nascentes democracias da região. Não somente os partidos de esquerda, mas todo o espectro político perdeu no processo altas doses de legitimidade e representatividade, na esteira da pulverização de velhas formas de sociabilidade e organização associadas à fase anterior do capitalismo. Produziu-se um paradoxo que consiste na consolidação da democracia enquanto "está en peligro la política" (CAVAROZZI e CASULLO, 2002, p. 10):

El eje competitivo entre los actores de la élite y los
partidos obreristas alrededor de un modelo de
desarrollo alternativo, ha perdido mucho de su
significado en una era de consenso ideológico,
convergencia organizacional, fragmentación social y
profesionalización política (ROBERTS, 2002, p. 74).

Nesse contexto, a questão democrática assumiu para a maioria das esquerdas da região um papel central - fato inédito até então. A defesa da democracia foi tradicionalmente problemática para as esquerdas, particularmente para as latino-americanas. As esquerdas da região tradicionalmente valorizaram concepções e aspectos substantivos da democracia. No entanto, setores significativos dessas esquerdas vêm reconhecendo seus valores representativos, tirando vantagem do processo de democratização da região ao se adaptarem com êxito ao jogo institucional. Fato igualmente inédito foi que,

longe de constituir um agente marginal ou anti-
sistema, o setor majoritário das mesmas foi ator
relevante no processo de construção das novas
democracias. A opção pela integração institucional
implicou mudanças relevantes dentro das esquerdas e
sobre os processos políticos (SERNA, 2004, p. 29).

O que foi apresentado sinteticamente nos parágrafos anteriores nos oferece algumas chaves para compreender as mutações sofridas pelas propostas sociais das esquerdas latino-americanas. A crise das esquerdas (do "socialismo real", do marxismo, da social-democracia e da própria noção de esquerda) certamente influiu na caminhada para um tratamento mais "realista", moderado e reformador da temática 
social. Partidos progressivamente independentes das referências socialistas e marxistas e mais afastados dos modelos organizativos clássicos das esquerdas (socialistas "de massa" ou "leninistas") poderiam ser considerados mais adequados às novas formas sociais em gestação na região - recepções e adaptações das transformações da modernidade nessa última quadra histórica (DOMINGUES, 2005). Teriam igualmente maior flexibilidade teórica e organizativa para operar a relativa diluição da idéia de igualdade em propostas de redução da pobreza e inclusão à cidadania. O socialismo passaria a ser posto na melhor das hipóteses num futuro longínquo, dando espaço a propostas de igualdade de oportunidades, integração, inclusão e democratização, sem necessidade de uma ruptura com o capitalismo.

Essas transformações, associadas ao questionamento dos diversos modelos "Estado-cêntricos" e ao avanço do neoliberalismo, podem ajudar a compreender a variação de enfoque notada, de propostas sociais basicamente estruturais e estatizantes para reformas mais específicas e focalizadas que apelariam agora ao apoio decisivo da iniciativa privada e da sociedade civil organizada. A progressiva aceitação da democracia política - associada a um processo de institucionalização, profissionalização e acúmulo de experiências nos legislativos e no poder local - reforçaria tal tendência "realista", favorecendo o desenvolvimento de propostas mais elaboradas, com metas e gastos definidos.

As mudanças nas concepções e programas sociais dessas esquerdas se relacionam em última análise ao seu processo de adaptação às profundas transformações vivenciadas na última quadra histórica, que permitiu a elas se fortalecer e chegar a governos nacionais. No entanto, com todas as referidas adaptações e diluições, deve-se reconhecer que elas mantiveram até a chegada ao poder o enfoque na justiça social e na defesa da redução da pobreza e (eventualmente) da desigualdade - ainda que numa chave agora mais difusa, de "direitos", de "oportunidades", de "sensibilidade social" e "ética". Tal enfoque, associado a um perfil até certo ponto contrário às idéias e políticas neoliberais, está no cerne do posicionamento 
"alternativo" e "progressista" dessas forças. Quando o neoliberalismo mostrou-se ineficiente para resolver os problemas históricos da região, chegando mesmo a agravá-los, e entrou em crise, surgiu a oportunidade para essas esquerdas latino-americanas aggiornadas serem guindadas ao poder como depositárias de um desejo difuso por "mudanças", e colocarem em prática suas propostas sociais elaboradas e adaptadas nos longos anos de oposição.

Esse processo de adaptação das esquerdas latino-americanas continuou em andamento durante seus governos progressistas, e a análise dos gastos sociais recentes mostra a grande atenção dada a políticas de transferência de renda. Partidos que na década de 1980 chegavam a defender a estatização, levando às últimas conseqüências a universalização dos serviços públicos, até o momento têm mostrado que seguem a tendência da focalização. Apresentados brevemente aqui, os gastos sociais desses quatro governos de esquerda mostram grande diversidade no que diz respeito à composição das cifras e a seu montante. Em comum, apesar da utilização de políticas focalizadas que contam com um componente monetário, eles apresentam esforços de alcance de um gasto mais progressivo, numa relação inversa à renda.

Ao longo dos anos 1990, tais políticas começaram a ser propostas e desenhadas pelos partidos estudados. No entanto, até a chegada ao poder, elas eram em geral apresentadas como propostas emergenciais, voltadas para o enfrentamento imediato da histórica situação de pobreza extrema da América Latina, aprofundada pelas políticas neoliberais hegemônicas nos últimos anos. Especificamente nos casos brasileiro e uruguaio, encontramos referências a essas políticas como componentes do que seria uma "primeira fase" no enfrentamento da questão social. Elas seriam substituídas progressivamente por investimentos mais universais, e por transformações na estrutura social e nas políticas econômicas. Talvez esta "primeira fase" esteja se prolongando mais que o previsto. Talvez políticas excepcionais estejam se tornando a regra.

REVISTA DEBATES, Porto Alegre, v. 2, n.1, p. 150-178, jan.-jun.2008. 
Julia Sant'Anna é doutoranda em Ciência Política no IUPERJ e assistente de coordenação do OPSA.

E-mail: jsantanna@iuperj.br

Fabricio Pereira da Silva é doutorando em Ciência Política e assistente de pesquisa no IUPERJ.

E-mail: fsilva@iuperj.br

\section{Referências:}

ALCÁNTARA, M. ¿Instituciones o máquinas ideológicas? Origen, programa y organización de los partidos políticos latinoamericanos. Barcelona: ICPS, 2004.

AVELINO FILHO, G. Democratization and social expenditure in Latin America, 1980-1994. 2000. 180 f. Tese (Doutorado em Ciência Política)Stanford University, [2000].

BAYLEY, M. A. Frente Amplio - la admirable alarma de 1971- Historia y documentos. Montevidéu: Cauce, 2005.

BOBBIO, N. Direita e esquerda - razões e significados de uma distinção política. São Paulo: Unesp, 1995.

BOLTANSKI, L.; CHIAPELLO, È. El nuevo espíritu del capitalismo. Madri: Akal, 2002.

BRASIL. Orçamento Social do Governo Federal 2001 - 2004. Brasília: Secretaria de Política Econômica/ Ministério da Fazenda, 2005.

BROWN, D. S.; HUNTER, W. Democracy and social spending in Latin America, 1980-92. The American Political Science Review, Cambridge, v. 23, n.4, p. 779-790, 1999.

CAVAROZZI, M.; CASULLO, E. Introduccíon. In: CAVAROZZI, M.; MEDINA, J. M. A. (Comps.). El asedio a la política- Los partidos latinoamericanos en la era neoliberal. Rosário: Homo Sapiens, 2002. p. 9-30.

CEPAL. Panorama social de América Latina 2005. Santiago do Chile: CEPAL, 2005.

CHAVEZ, D. Montevideo. De la participación popular al 'buen gobierno. In: CHAVEZ, D.; GOLDFRANK, B. (Eds.). La izquierda en la ciudad participación en los gobiernos locales de América Latina. Barcelona: Icaria, 2004. p. 235-256.

CHILE. Pobreza, distribución del ingreso e impacto distributivo del gasto social. Santiago do Chile: División Social del Ministerio de Planificación y Cooperación, 2004. (Serie CASEN 2003,1). 
COHEN, E. Los desafíos de las políticas y la gestión social en América Latina. Revista do Serviço Público, Brasilia, v.56, n.4, p.403-417, 2005.

DOMINGUES, J. M. Sociología brasileña, Latinoamérica y la tercera fase de la modernidad. Estudios Sociológicos, University of North Carolina, v. 23, n. 68, p.591-609, 2005.

FLOOD, C.; GRAU, C.; MELGAR, A. Análisis del gasto público social. Washington: Banco Interamericano de Desarrollo, 2005. (Serie de Estudios económicos y sociales).

FRENTE AMPLA. Portal de información del EPFA. Disponível em: <http://www.epfaprensa.org>. Acesso em: 20 mar 2008.

GIDDENS, A. As consequências da modernidade. São Paulo: Unesp, 1991.

GOBIERNO DE CHILE. Gobierno de Chile Disponível em: <http://www.gobiernodechile.cl>. Acesso em: 20 mar 2008.

ILLANES, M. A.; RIESCO, M. Developmental Welfare State and social change in Chile. In: RIESCO, M. (Ed.). Latin America: a new developmental Welfare State model in the making? Houndmills: UNRISD- Palgrave, 2007. p. 378-414.

INSTITUTO CIDADANIA. Projeto Fome Zero. Uma proposta de política de segurança alimentar para o Brasil. São Paulo: Instituto Cidadania, 2001.

KAUFMAN, R.; UBIERGO, A. S. Globalization, domestic politics and social spending in Latin America: a time-series cross-section analysis, 19731997. World Politics, Washington D. C., v. 53, p.553-87, 2001.

MINISTÉRIO DO PLANEJAMENTO DO BRASIL. Planejamento- Ministério do planejamento, orçamento e gestão. Disponível em: <http://www.planejamento.gov.br>. Acesso em: 20 mar 2008.

MOVIMENTO AO SOCIALISMO. Instrumento Político por la soberania de los pueblos. Disponível em: <http://www.masbolivia.org>. Acesso em: 20 mar 2008.

OCAMPO, J. A. Distribución del ingreso, pobreza y gasto social en América Latina. Revista de la CEPAL, Santiago, n. 65, p.7-14, ago. 1998.

PARTIDO DOS TRABALHADORES. Partido dos Trabalhadores resoluções de encontros e congressos (1979-1998). São Paulo: Fundação Perseu Abramo, 1998. 
PARTIDO DOS TRABALHADORES. Partido dos Trabalhadores- Diretório Nacional. Disponível em: <http://www.pt.org.br>. Acesso em: 20 mar 2008.

PARTIDO SOCIALISTA DO CHILE. Partido Socialista do Chile On Line. Disponível em: <http://www.pschile.cl>. Acesso em: 20 mar 2008.

POCHMANN, M. Evidências recentes na relação entre gasto social e desigualdade de renda no Brasil. Pensar $B H$ - Política social, Belo Horizonte, n. 13, p. 5-9, set.-nov. 2005.

PORTAL SALVADOR ALLENDE. Salvador Allende Gossens. Disponível em: <http://www.salvador-allende.cl>. Acesso em: 20 mar 2008.

ROBERTS, K. El sistema de partidos y la transformación de la representación política en la era neoliberal latinoamericana. In: CAVAROZZI, M.; MEDINA, J. M. A. (Comps.). El asedio a la política- Los partidos latinoamericanos en la era neoliberal. Rosário: Homo Sapiens, 2002. p. 55-76.

SANTOS, C. C. B. Ideologia, partidos políticos e gasto social na América Latina (1980-1999). 2006. 178 f. Tese (Doutorado em Ciência Política) Instituto Universitário de Pesquisas do Rio de Janeiro, [2006].

SERNA, M. Reconversão democrática das esquerdas no Cone Sul trajetórias e desafios na Argentina, Brasil e Uruguai. Bauru: EDUSC, 2004.

SOCIALISMO CHILENO. Portal del Socialismo Chileno. Disponível em: <http://www.socialismo-chileno.org >. Acesso em: 20 mar 2008.

UNICEF. Bolívia: Gasto Social Funcional y Gasto Social para la Niñez 2000 - 2004. La Paz: Unicef e Udape, 2006.

WAGNER, P. A sociology of modernity: liberty and discipline. Londres/ Nova Iorque: Routledge, 2004. 